\title{
SOSIALISASI PPH UMKM BAGI ANAK REMAJA DI JAKARTA BARAT
}

\author{
Yuniarwati, Andrian \\ Program Studi Pendidikan Profesi Akuntan, Universitas Tarumanagara \\ Surel: yuniarwati@fe.untar.ac.id
}

\begin{abstract}
Developments in the era of globalization rely on the economic sector as a measure of success by the government. Micro, Small and Medium Enterprises (MSMEs) are currently starting to develop well and are able to generate profits. Therefore, it is appropriate for MSMEs to participate in increasing state revenues through the payment of Income Tax. Bhinneka Tunggal Ika High School as a PKM partner requires enriching students' insights related to MSME Income Tax and how to use e-commerce to start a MSME business so that based on the Statement Letter from the Principal, Mr. Edi Fredi S Ag on August 9, 2021. With this PKM, the expected target is to provide a true understanding of the MSME Income Tax. This PKM activity is planned to be carried out by filling out a study schedule and can be followed by teachers as well. Bhinneka Tunggal Ika High School is located at Jl. KH.Moh.Mansyur No.222 A, RT.10/RW.5, Tanah Cereal, Kec. Tambora. In the training, the MSME PPh Module will be distributed as the output of this PKM so that it can be taken home and read by the high school students for future learning materials. The method of implementing this training will be done with tutorials and discussions as well as questions and answers which will all be held via zoom. In the PKM training, it can be seen that the Bhinneka Tunggal Ika High School students are enthusiastic in asking and answering the material given. Bhinneka Tunggal Ika High School students also listened and understood the theories discussed and answered all the questions asked correctly. Therefore, it can be said that this training was carried out well.
\end{abstract}

Keywords: Tax, MSMEs, SMA Bhinneka Tunggal Ika

\begin{abstract}
ABSTRAK
Perkembangan dalam dunia globalisasi sangatlah bergantung pada sektor ekonomi sebagai ukuran keberhasilan yang dilakukan pemerintah. Pada saat ini, Usaha Mikro Kecil dan Menengah (UMKM) telah berkembang dengan baik dan menghasilkan laba yang besar. Oleh karena itu, UMKM juga turut berpartisipasi dalam menambah penerimaan negara melalui pebayaran Pajak Penghasilan. SMA Bhinneka Tunggal Ika sebagai mitra PKM ini membutuhkan pengayaan wawasan siswa-siswi nya terkait dengan PPh UMKM serta cara menggunakan e-commerce untuk memulai bisnis UMKM sehingga berdasarkan Surat Pernyataan dari Kepala Sekolah Bpk. Edi Fredi S Ag pada tanggal 9 Agustus 2021. kami melaksanakan kegiatan Pengabdian Kepada Masyarakat ini. Dengan PKM ini, target yang diharapkan dapat memberi pemahaman yang benar terkait Pajak Penghasilan UMKM. Kegiatan PKM ini direncanakan dilaksanakan dengan mengisi jadwal belajar dan dapat diikuti oleh guru-guru juga. SMA Bhinneka Tunggal Ika beralamat di Jl. KH.Moh.Mansyur No.222 A, RT.10/RW.5, Tanah Sereal, Kec. Tambora. Dalam pelatihan akan dibagikan Modul PPh UMKM sebagai luaran PKM ini sehingga dapat dibawa pulang dan dibaca oleh siswa-siswi SMA tersebut untuk bahan pembelajaran pada masa mendatang. Metode pelaksanaan pelatihan ini akan dilakukan dengan tutorial dan diskusi serta tanya jawab yang seluruhnya akan diselenggarakan via zoom. Pada pelatihan PKM dapat dilihat antusias siswa-siswi SMA Bhinneka Tunggal ika dalam bertanya dan menjawab materi yang diberikan. Siswa-siswi SMA Bhinneka Tunggal ika juga telah mendengarkan dan mengerti tentang teori yang dibahas dan menjawab seluruh pertanyaan yang diajukan dengan tepat. Oleh karena itu, dapat disimpulkan bahwa pelatihan ini sudah terlaksana dengan baik.
\end{abstract}

Kata kunci: Pajak, UMKM, SMA Bhinneka Tunggal Ika

\section{PENDAHULUAN}

Sekolah Bhinneka Tunggal Ika (BTIKA) merupakan sekolah asimilasi pertama di Indonesia. Inisiatif Alm.Bpk Mohammad Hatta (Wakil Presiden Indonesia) yang mengganti nama sekolah Ta Tung menjadi Sekolah Bhinneka Tunggal Ika pada tahun 1971 yang melibatkan generasi bangsa tanpa memandang suku, ras, dan agama. Sekolah Bhinneka Tunggal Ika didirikan oleh Alm. Bpk Djoko Haryono yang awalnya bernama Ta Tung. Rasa keprihatinan terhadap dunia pendidikan pada masa tahun 1968 dan karena banyak anak Indonesia yang putus dan tidak 
bersekolah yang memotivasi pendirian sekolah ini. Hingga saat ini Yayasan Pendidikan Bhinneka Tunggal Ika yang menaungi Sekolah Bhinneka Tunggal Ika memiliki asas Pancasila turut berpartisipasi dalam pembangunan bidang Pendidikan, pelayanan sosial lainnya, serta mempersiapkan tenaga-tenaga terampil dalam segala bidang. Kegiatan yang dilakukan adalah pembelajaran umum maupun kejuruan sebagai bentuk upaya mencerdaskan generasi muda dengan membantu terbentuknya pribadi yang utuh dan yang menghargai perbedaan. www.btika.sch.id

Visi SMA Bhinneka Tunggal Ika menjadi lembaga pendidikan nasional terkemuka dan modern yang turut serta membangun generasi penerus bangsa dalam Ilmu, Iman dan Karakter tanpa memandang Suku, Ras dan Agama berasaskan Pancasila. Misi SMA Bhinneka Tunggal Ika mengembangkan potensi peserta didik secara optimal melalui pendidikan karakter, pengajaran bermutu, toleran dan menghargai semua perbedaan yang ada, melalui peserta didik yang dipercayakan orang tua dan wali murid.

Pendidikan karakter yang mencakup pemberdayaan potensi dan pembudayaan peserta didik guna membangun karakter pribadi yang unik, baik sebagai warga negara Indonesia, pengajaran bermutu dengan cara membuat peserta didik ikut terlibat dalam pembelajaran di kelas seperti adanya sesi tanya jawab agar pembelajaran dapat terlaksana dengan optimal, menekankan rasa toleran dengan cara menanamkan hubungan antar sesama manusia yang berbeda ras, suku, agama agar nantinya dapat bersosialisasi dengan masyarakat yang lain dengan baik, dan menghargai perbedaan dengan cara melalui pendidikan multikultural dan pemahaman, akan menumbuhkan rasa kesadaran tentang pentingnya menghargai, mengakui, dan menerima keberagaman yang ada. Di tingkat SMA \& Kejuruan diselenggarakan program pendidikan yang beragam dan seimbang secara akademis demi mempersiapkan siswa usia 16 hingga 19 tahun untuk sukses memasuki jenjang pendidikan lanjutan di tingkat universitas ternama dan kehidupan di masyarakat.

Usaha mikro, kecil dan menengah (UMKM) merupakan bisnis yang ada karena diperlukan oleh suatu negara. UMKM telah terbukti dapat bertahan ketika negara Indonesia dilanda badai krisis ekonomi sejak Juli 1997. Menurut Sarfiah (2019), UMKM adalah salah satu sektor usaha penopang utama yang dapat memberikan banyak lapangan kerja bagi masyarakat. Hal ini tentunya akan berpengaruh dengan jumlah pengangguran yang ada.

Siswa-siswi SMA Bhinneka Tunggal Ika merupakan salah satu generasi penerus bangsa dimasa mendatang. Pajak merupakan hal yang penting untuk diketahui oleh siswa-siswi sebagai bekal mereka dimasa mendatang setelah memasuki dunia kerja. Pajak adalah salah satu pemasukan negara yang terbesar dan dapat menopang kestabilan ekonomi negara. UMKM sendiri merupakan salah satu penyumbang pajak terbesar bagi negara. Berdasarkan data BPS dan Kementerian Koperasi dalam Wahyudin (2013:27) menyebutkan bahwa dari semua kelas usaha yang ada di Indonesia, sebesar 99\% nya merupakan usaha skala kecil. Hal ini berarti hampir semua usaha yang ada di Indonesia merupakan kelas usaha kecil sedangkan sebesar $1 \%$ usaha berkelas menengah dan besar.

Oleh karena itu, kami memberikan pelatihan ini agar dapat mengatasi masalah mitra. Sehingga dikemudian hari siswa-siswi sudah memahami tentang apa itu fungsi pajak, bagaimana cara hitung pajak dan bagaimana cara menjalankan bisnis UMKM dengan memanfaatkan kemajuan teknologi yang sudah ada.

UMKM merupakan penyumbang pemasukan negara yang terbesar. Di tengah pandemi global COVID-19 yang dialami oleh seluruh dunia, UMKM menjadi penopang ekonomi nasional ditengah kondisi global yang tidak menentu. Banyak pekerja atau karyawan yang kelihangan pekerjaannya dimasa pandemi COVID-19 dan memilih untuk membuka usahanya sendiri dengan kemampuan dan modal secukupnya agar dapat melanjutkan hidup. Oleh karena itu, 
pemerintah juga berusaha membantu memperkenalkan dan membangkitkan UMKM yang ada pada masa pandemi global COVID-19 ini. Semua pihak harus beradaptasi menjadi serba daring agar dapat mengatasi COVID-19 dan UMKM tetap dapat berjalan. https://www.kompas.com/parapuan/read/532710842/jadi-penopang-perekonomian-di-masapandemi-yuk-dukung-umkm-indonesia

UMKM dapat diartikan sebagai bisnis yang telah dijalankan oleh seorang individu, rumah tangga atau badan usaha berskala kecil. Suatu bisnis dapat dikategorikan masuk dalam UMKM dilihat dari batas omset pertahun, aset yang dipunya dan jumlah karyawan yang dimiliki, Menurut Sukirno (2004) Usaha Mikro, Kecil, dan Menengah (UMKM) mempunyai artian yang lain pada setiap orang, kelompok bahkan Undang-undang. Menurut Undang-Undang nomor 20 tahun 2008 (UMKM) dapat diartikan sebagai:

- Usaha mikro adalah usaha aktif yang dipunyai oleh orang pribadi atau badan usaha perseorangan yang telah memenuhi syarat-syarat usaha mikro yang telah diatur dalam undang-undang ini.

- Usaha kecil adalah usaha aktif yang berdiri sendiri dan dijalankan oleh orang pribadi atau badan usaha yang bukan merupakan anak perusahaan atau cabang perusahaan usaha menengah atau usaha besar.

- Usaha menengah adalah usaha aktif yang berdiri sendiri dan dijalankan oleh orang pribadi atau badan usaha yang bukan merupakan anak perusahaan atau cabang perusahaan usaha menengah atau usaha besar dengan jumlah kekayaan bersih atau hasil penjualan tahunan sebagaimana yang telah diatur oleh undang undang ini.

Pajak merupakan sumber pendapatan negara terbesar. Di Indonesia, pajak sangat berpengaruh besar dalam kemajuan pembangunan suatu negara. Pajak yang sudah terkumpul tersebut dapat digunakan untuk membiayai kegiatan pemerintahaan maupun untuk meningkatkan kesejahteraan masyarakat. Seperti pembangunan trotoar, JPO yang menunjang masyarakat dalam beraktivitas. Menurut Undang-Undang Nomor 28 tahun 2008 pajak adalah iuran wajib masyarakat kepada negara yang terutang oleh orang pribadi atau badan usaha yang sifatnya memaksa dan wajib pajak tidak mendapatkan imbalan secara langsung melainkan pajak tersebut digunakan untuk pembangunan negara.

PPh UMKM merupakan salah satu pajak terbesar karena banyaknya jumlah UMKM di Indonesia. Menurut Peraturan Pemerintah (PP) Republik Indonesia Nomor 46 Tahun 2013, PPh final MKM adalah pajak atas omzet dari usaha yang diperoleh pemilik usaha. Namun pada tanggal 1 Juli 2018 pemerintah telah mengeluarkan peraturan baru PP Nomor 23 Tahun 2018 mengenai tarif baru PPh Final UMKM yang menjadi 0,5\%.

Dalam menjalankan bisnis UMKM, sebagai masyarakat yang wajib pajak juga harus memenuhi kewajibannya dalam membayar pajak. Alasan UMKM perlu membayar pajak adalah karena UMKM juga merupakan suatu kegiatan jual beli yang mendapatkan penghasilan dan laba. Semua hal bisnis yang memperoleh penghasilan harus memenuhi kewajiban dalam membayar pajak penghasilan kepada negara. Pada UMKM yang memiliki omzet maksimal Rp 4.800.000.000,00 per tahun maka dapat menggunakan PPh Final 0,5\%. Jika UMKM tidak berbentuk badan usaha maka cara menghitung pajaknya menggunakan laporan keuangan fiscal. Namun jika UMKM berbentuk badan usaha maka penyajian laporan keuangan dibuat melalui proses pembukuan. (Isroah, 2013).

Tarif pajak $0,5 \%$ pada UMKM hanya berlaku untuk:

- UMKM yang memiliki omzet kurang dari Rp 4.800.000.000 per satu tahun pajak. Seperti usaha dagang, toko, kios, rumah makan dan salon. 
- UMKM konvensional baik offline maupun online (marketplace)

Tarif pajak 0,5\% juga ada batas waktunya seperti yang tertera pada PP Nomor 23 tahun 2018 yaitu wajib pajak perseorangan selama 7 tahun, wajib pajak badan berbentuk koperasi dan firma selama 4 tahun. Tarif pajak istimewa ini untuk wajib pajak badan koperasi, firma hanya berlaku hingga akhir tahun 2021 dan akan mulai melakukan pembukuan lagi pada tahun 2022. Pajak UMKM dapat dibayar dengan cara datang langsung ke kantor pos atau perbankan yang telah ditunjuk mentri keuangan dan juga bisa dibayar di mesin ATM.

\section{METODE PELAKSANAAN PKM}

Pelaksanaan pelatihan PKM ini dilakukan pada Jumat, 3 September 2021 via zoom meeting. Pelatihan dilakukan dengan memberikan modul teori tentang UMKM dan PPh UMKM. Didalam pelatihan ini juga dibahas tentang cara memanfaatkan e-commerce untuk memulai UMKM. Setelah pembahasan teori dilanjutkan dengan sesi tanya jawab. Di bawah ini susunan acara metode pelaksanaan PKM yang dilaksanakan:

Sessi 1: Sessi tanya jawab terkait PPh UMKM

Sessi 2: Pelatihan UMKM

Sessi 3: Sessi tanya jawab untuk evaluasi pemahaman materi

Pada saat pelaksanaan kami hadir berdua (satu orang dosen dan satu orang mahasiswa) di zoom meeting. Lokasi Sekolah Bhinneka Tunggal Ika di Jl. KH.Moh.Mansyur No.222 A, RT.10/RW.5, Tanah Sereal, Kec. Tambora. Pelatihan ini akan membagikan voucher uang elektronik @ Rp.50.000, kepada 10 siswa yang berhasil menjawab pertanyaan di awal (5 siswa) dan di akhir pelatihan (5 siswa). Modul akan kami unggah di file zoom meeting tersebut. Souvenir dan hadiah akan diserahkan saat kegiatan berlangsung.

Pada akhir pelatihan akan disebarkan angket untuk evaluasi jalannya PKM ini. Laporan Pertanggung Jawaban kepada LPPM dibuat setelah PKM selesai dilaksanakan dan pada saat acara Senapenmas pada tahun 2021 dipublikasikan dalam bentuk artikel. Berdasarkan hasil angket yang dibagikan dapat diketahui topik yang diminati siswa/siswi SMA Bhinneka Tunggal Ika ini dan dapat direncanakan untuk topik pelatihan semester berikutnya.

Fakultas Ekonomi dan Bisnis Universitas Tarumanagara berdiri sejak tahun 1959 memiliki Program Studi Akuntansi dan Program Studi Manajemen serta Program Studi Magister Akuntansi dan Pendidikan Profesi Akuntansi, sehingga sudah selayaknya menyelenggarakan Pengabdian Kepada Masyarakat agar ada transfer pengetahuan yang lebih luas. Di sisi lain, dalam Fakultas Ekonomi \& Bisnis UNTAR sudah banyak dosen yang telah tersertifikasi dan diwajibkan membuat kegiatan Tridharma Perguruan Tinggi antara lain kegiatan Pengabdian kepada Masyarakat (PKM). Tim PKM ini terdiri dari dua orang, dimana satu orang dosen dan satu orang mahasiswa.

Dua orang tim PKM yang melakukan pelatihan PPh UMKM kepada siswa/siswi SMA Bhinneka Tunggal Ika adalah:

Yuniarwati SE., MM., Ak., CA Kepakaran : Akuntansi dan Pajak

Bertugas : mengkoordinasi dan melaksanakan PKM.

Satu orang mahasiswa S1 Manajemen yang dilibatkan dalam PKM ini adalah:

Andrian / 115170003

Kepakaran : Manajemen dan Teknologi Informatika

Bertugas : membantu pelaksanaan PKM dengan mendampingi para siswa/siswi untuk dapat mengikuti materi yang disampaikan 


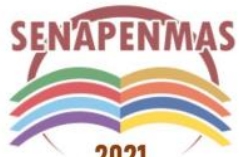

2021
Seminar Nasional Hasil Penelitian dan Pengabdian Kepada Masyarakat 2021 Pengembangan Ekonomi Bangsa Melalui Inovasi Digital Hasil Penelitian dan Pengabdian Kepada Masyarakat Jakarta, 21 Oktober 2021

\section{HASIL DAN PEMBAHASAN}

Diawali dengan survey pada awal Agustus 2021 pada sekolah SMA Bhinneka Tunggal Ika untuk menindaklanjuti pelaksanaan PKM semester sebelumnya, topik yang diminati siswa/siswi SMA Bhinneka Tunggal Ika ditelaah kembali. Setelah survey, pelaksanaan PKM dilakukan sebagai tindak lanjut PKM semester sebelumnya melalui surat permohonan dari Bapak Edi Fredi S.Ag selaku kepala sekolah SMA Bhinneka Tunggal Ika pada tanggal 9 Agustus 2021 untuk membuat pelatihan. Kegiatan PKM ini dilakukan pada Jumat, 3 September 2021 Pk. 09.00 - 12.00. Pelatihan dibagi menjadi 3 sessi, dimana sessi pertama merupakan sessi tanya jawab terkait $\mathrm{PPh}$ UMKM. Sessi selanjutnya merupakan sesi pelatihan dan pemaparan teori- teori. Dilanjutkan dengan sessi terakhir yaitu sessi tanya jawab untuk evaluasi pemahaman materi yang telah diberikan. Pada bagian akhir pelatihan juga disebarkan angket untuk evaluasi jalannya PKM dan mengenai topik lain yang diminati siswa/siswi SMA Bhinneka Tunggal Ika untuk kelanjutan PKM.

Dari pertanyaan terbuka diungkap persepsi responden bahwa pelatihan PPh UMKM dapat digunakan untuk menambah pengetahuan perpajakan dan UMKM untuk bekal dan pembelajaran dimasa mendatang saat memasuki dunia kerja. Saran responden untuk topik UMKM adalah aplikasi nyata yang tepat untuk dipakai di masa mendatang dan bagaimana yang cara yang tepat untuk menjalankan bisnis. Dalam pelaksanaan PKM telah dijelaskan tentang pentingnya pajak, cara menghitung pajak dan cara memanfaatkan teknologi untuk memulai bisnis UMKM. PKM ini telah terlaksana dengan baik, hal ini dapat dilihat dari antusias siswa/siswi SMA Bhinneka Tunggal Ika dalam bertanya dan menjawab materi yang diberikan. Siswa/siswi SMA Bhinneka Tunggal Ika juga telah mendengarkan dan mengerti pembahasan teori dan menjawab seluruh pertanyaan yang diajukan dengan benar. Aktivitas pelaksanaan PKM dapat dilihat pada gambar foto-foto di bawah ini.

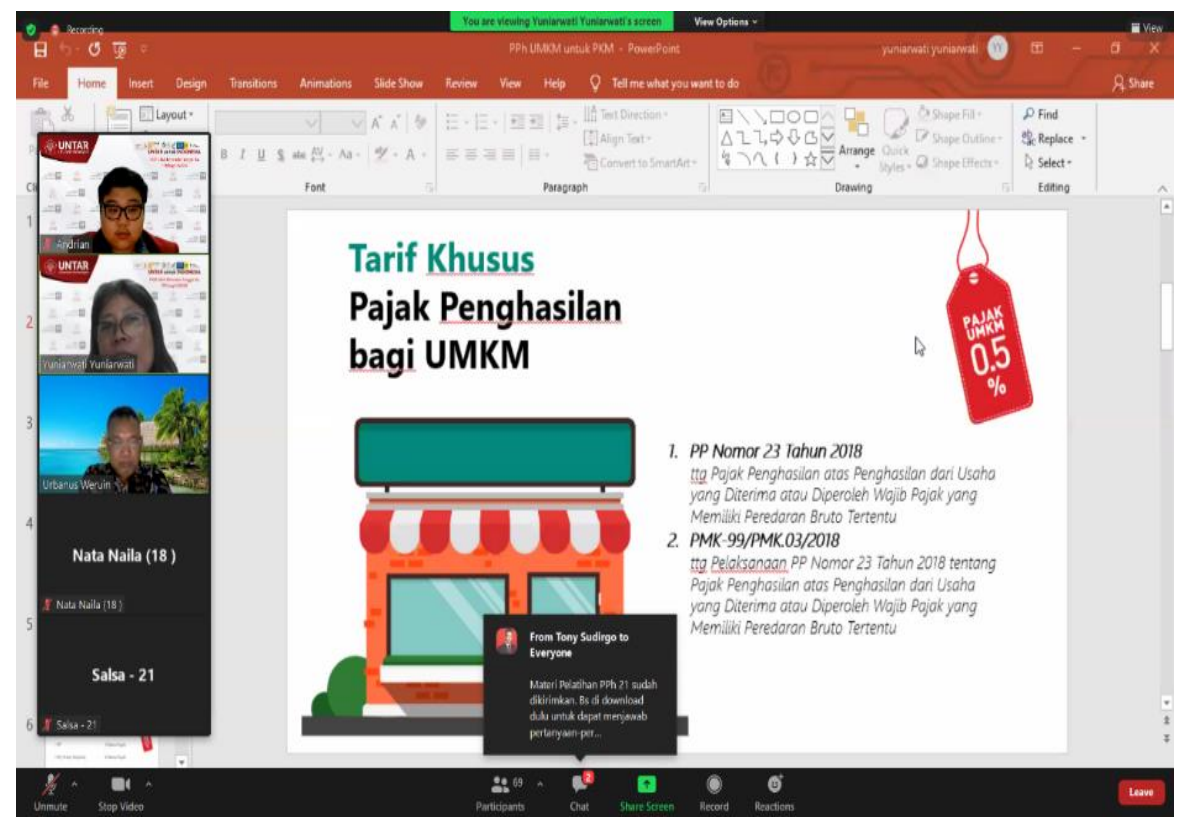

Gambar 1.Pelaksanaan PKM (a) 


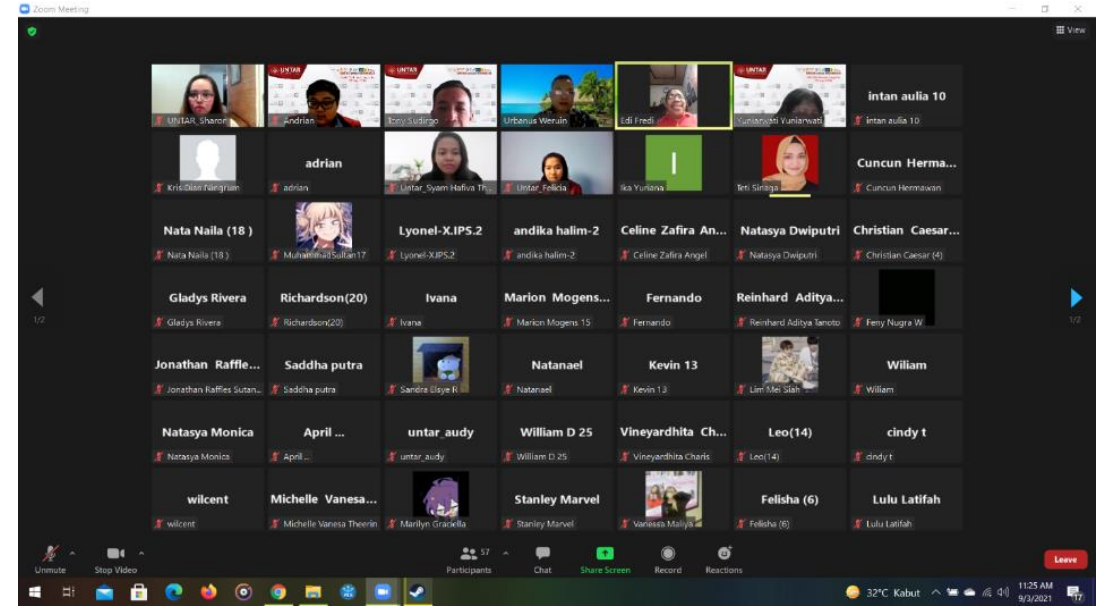

Gambar 2. Pelaksanaan PKM (b)

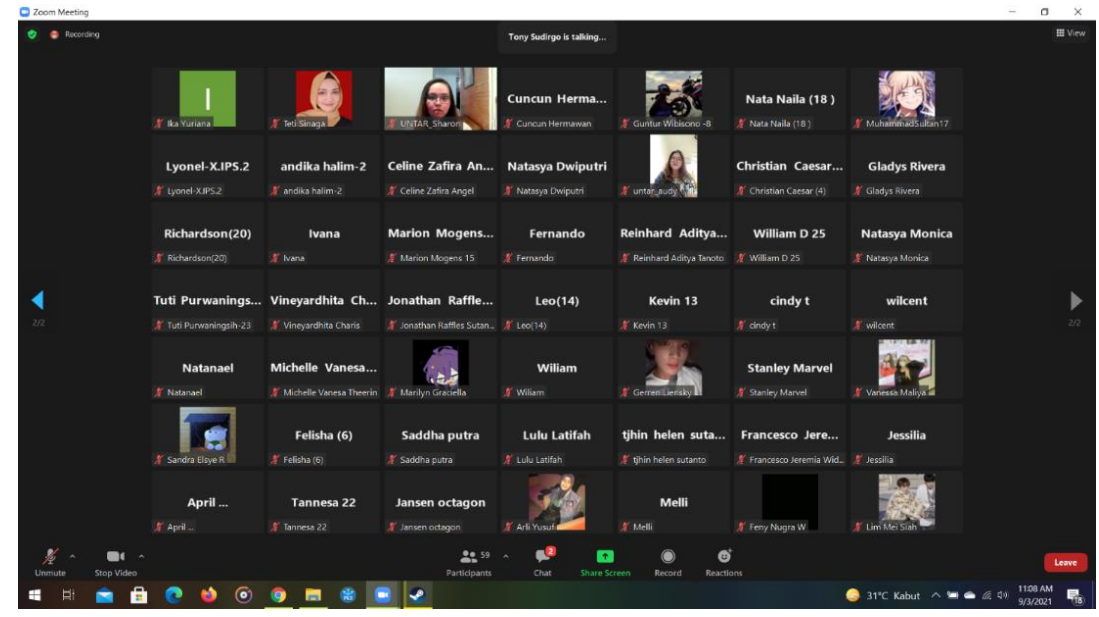

Gambar 3.Pelaksanaan PKM (c)

\section{KESIMPULAN DAN SARAN}

PKM Pelatihan PPh UMKM kepada siswa/siswi SMA Bhinneka Tunggal Ika ini telah terlaksana dengan baik. Siswa/siswi SMA Bhinneka Tunggal Ika juga sangat antusias dalam mendengarkan serta bertanya kepada tim PKM. Keberlanjutan pelaksanaan PKM juga dibutuhkan agar siswa/siswi SMA Bhinneka Tunggal Ika tahun selanjutnya dapat memahami tentang bisnis UMKM serta pentingnya membayar pajak bagi negara (PPh UMKM). Saya berharap dengan pelatihan ini dapat membekali siswa/siswi SMA Bhinneka Tunggal Ika dalam memulai bisnis UMKM dimasa mendatang.

Di masa depan selanjutnya PKM dapat menindak lanjuti PKM sebelumnya agar terdapat kesinambungan dengan pembekalan topik yang dibutuhkan dan di minati seperti yang dikemukakan dalam angket PKM sebelumnya. Siswa/siswi perlu terus diberikan pelatihan pada tahun selanjutnya karena akan ada siswa/siswi baru yang masuk dan lulus. Disamping itu, topik lain seperti matematika, bisnis, e-commerce, digital marketing juga dapat dilakukan untuk pembekalan siswa/siswi di jaman perkembangan teknologi seperti sekarang ini. 


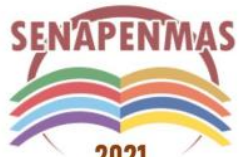

2021
Seminar Nasional Hasil Penelitian dan Pengabdian Kepada Masyarakat 2021 Pengembangan Ekonomi Bangsa Melalui Inovasi Digital Hasil Penelitian dan Pengabdian Kepada Masyarakat Jakarta, 21 Oktober 2021

\section{Ucapan Terima Kasih}

Saya mengucapkan terima kasih kepada Lembaga Penelitian dan Pengabdian Kepada Masyarakat (LPPM) Universitas Tarumanagara yang telah memberikan dukungan dana untuk penelitian ini. Saya juga berterima kasih kepada Bapak Edi Fredi S.Ag selaku kepala sekolah SMA Bhinneka Tunggal Ika yang telah memberikan kami kesempatan untuk mengadakan pelatihan kepada siswa-siswi SMA Bhineka Tunggal Ika. Acknowledgement ini ditulis di bawah kesimpulan, sebelum referensi. Selanjutnya saya juga mengucapkan terima kasih kepada Andrian, mahasiswa Universitas Tarumanagara selaku asisten pelaksana PKM ini.

\section{REFERENSI}

Adrianjara, D. (2021, Mei 25). Jadi penopang perekonomian di masa pandemic, yuk dukung UMKM Indonesia!. Diakses dari https://www.kompas.com/parapuan/read/532710842/jadi-penopang-perekonomian-dimasa-pandemi-yuk-dukung-umkm-indonesia

Idris yanto, 2009. Sektor UMKM di Indonesia: Profil, Masalah, dan Strategi Pemberdayaan. Jurnal Kajian Ekonomi dan Bisnis OIKOSNOMOS. Volume 2, Nomor 1/ Januari 2009. ISSN 1979-1607. LPPEB FIS - UNG Inc.

Isroah, 2013, Perhitungan pajak penghasilan bagi UMKM, Jurnal Nominal Vol II no 1 tahun 2013; https://journal.uny.ac.id/index.php/nominal/article/view/1649/1373

Kementerian Koperasi dan Usaha Kecil dan Menengah Republik Indonesia, Peran Usaha Mikro, kecil, dan Menengah dalam Pembangunan Ekonomi Nasional; Sasaran Pembangunan Ekonomi (Jakarta: Kementerian Koperasi dan Usaha Kecil dan Menengah Republik Indonesia, 2005)

Sarfiah, Atmaja, Verawati. 2019, UMKM Sebagai pilar membangun ekonomi bangsa, Jurnal $\begin{array}{lllllll}\text { REP } & \text { Vol } & 4 & \text { No } & 1 & \text { tahun } & \text { 2019; }\end{array}$ https://jurnal.untidar.ac.id/index.php/REP/article/view/1952/pdf_1

Sari, Fitriana Monica; 2019; 10 Peluang Bisnis yang Bisa Dicoba Anak SMA; https://www.liputan6.com/bisnis/read/3921520/10-peluang-bisnis-yang-bisa-dicobaanak-sma

Sukirno, S. 2004. Makroekonomi Suatu Pengantar. Rajawali Pers. Jakarta. Undang-Undang nomor 20 tahun 2008 tentang Usaha Mikro, Kecil, dan Menengah, UMKM.

www.btika.sch.id 
Seminar Nasional Hasil Penelitian dan Pengabdian Kepada Masyarakat 2021

Pengembangan Ekonomi Bangsa Melalui Inovasi Digital Hasil Penelitian dan

Pengabdian Kepada Masyarakat

Jakarta, 21 Oktober 2021

(halaman kosong) 